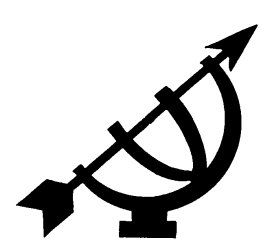

\title{
Performatiwiteit en die hedendaagse skool(hoof)
}

\author{
J.L. van der Walt, P.J. Mentz, J.A. Breed \& L.D. Coetsee \\ Fakulteit Opvoedingswetenskappe \\ Potchefstroomkampus \\ Noordwes-Universiteit \\ POTCHEFSTROOM \\ E-pos: jlvdwalt@aerosat.co.za \\ Kobus.Mentz@nwu.ac.za \\ jabreed@gimmies.co.za \\ leon11@vodamail.co.za
}

\begin{abstract}
Performativity and the modern school (principal)

Based on observations in the field of education management science, including the results of a recent empirical survey, we concluded that schools and their principals have become inundated with the demands for performativity, i.e. the demand to achieve in measurable terms as well as submit to the cult of efficiency and effectiveness. After briefly considering recent developments and changes in schools and in the work of school principals, we refer to the findings of the empirical survey. This is followed by a discussion of three key objections to performativity in schools and in the work of principals, namely the reductionism that it presupposes, its non-pedagogical tendencies and its negative effects on the school as a societal relationship. The discussion is conducted within a Christian-reformational frame of reference.
\end{abstract}

\section{Opsomming}

\section{Performatiwiteit en die hedendaagse skool(hoof)}

Op grond van waarnemings op die terrein van onderwysbestuurswetenskap, insluitende die resultate van 'n empiriese ondersoek, is tot die gevolgtrekking gekom dat skole en hulle hoofde deesdae neig om deur die eise van performatiwiteit verswelg te raak, dit wil sê die eis dat hulle in meetbare terme moet presteer en hulle aan die kultus van "efficiency and effectiveness" behoort te onderwerp. Na 'n kort beskrywing van 
onlangse verwikkelings en veranderings in skole en in die werk van skoolhoofde word na die bevindings voortvloeiend uit die empiriese ondersoek verwys. Dit word opgevolg deur ' $n$ bespreking van drie kernbesware teen performatiwiteit op skole en op die werk van skoolhoofde, te wete die reduksionisme wat dit vooronderstel, die onpedagogiese neigings wat dit inhou en die negatiewe uitwerking daarvan op die skool as samelewingsverband. Die bespreking geskied vanuit 'n Christelik-reformatoriese denkraamwerk.

\section{Oriëntering en metodologie}

Op grond van ondersoeke wat onlangs ingestel is, is tot die gevolgtrekking gekom dat skoolhoofde sedert die sewentigerjare voor die eise van performatiwiteit begin swig het. Die gevolgtrekking rus op konseptueel-teoretiese ondersoeke na die veranderinge wat die skool oor die eeue ondergaan het, die gepaardgaande veranderings in die rol van skoolhoofde, asook op 'n empiriese ondersoek wat ingestel is na die sienings van skoolhoofde in die Gauteng-provinsie van Suid-Afrika. Dit wil voorkom asof die probleem 'n (wêreld-)wye omvang het (vgl. Welch, 1998). ${ }^{1}$

Die artikel gee 'n oorsig van die ondersoeke wat gelei het tot die bevinding dat skoolhoofde hulself nie meer in die eerste instansie sien as opvoedende onderwysleiers/pedagogiese leiers nie, maar eerder as besigheidsleiers/hoofuitvoerende beamptes van hulle skole. Die doel van die ondersoek is om vanuit 'n Christelik-reformatoriese denkraamwerk oor die kwessie van performatiwiteit in die onderwys te kan oordeel, met spesiale verwysing na die rol van die skoolhoof. Die artikel begin met 'n beknopte oorsig van die veran-

1 Een van die anonieme keurders van hierdie artikel skryf in sy/haar kommentaar:

Een punt van kommentaar op die artikel lui dat die analises van die huidige praktyke in die skoolonderwys baie goed korreleer met analises van die tendense in die universiteitsonderwys. In albei gevalle gegee die literatuur en ervaring op internasionale kongresse - is die pyn by die 'werkersklas' en hulle belewenisse presies soos die artikel dit uitspel. Hierdie pynbelewenis word nie net in die reformatoriese kring gevind nie, maar ook in die Katolieke kring (Gerard Walmsley se 2008-Stokerlesing is hiervan 'n goeie voorbeeld) en in die konserwatiewer humanistiese kring. Performatiwiteitsopvoeding is opvoeding tot selfsug. Die toenemende geweld in die hedendaagse samelewing en in die besonder die geweld in skole in 'beskaafde' lande toon aan dat daar 'n opvoedingskrisis in alle samelewingsverbande aan die gang is. Plagiaat is maar een van die performatiwiteitsafwykings. Swak, diskriminerende prestasie-evaluerings deur die hiërargie is 'n ander een. Die jeugselfmoordsyfer (die gemiddelde ouderdom val amper tweejaarliks) dui op iets soortgelyks. 
derende rol en struktuur van die skool, die verander(en)de rol van die skoolhoof, en die bevindings van 'n empiriese ondersoek. Daarna volg 'n kritiese bespreking van performatiwiteit in die onderwys, veral soos dit tot uitdrukking kom in die professionele werk van 'n skoolhoof.

Hierdie benadering staan op twee metodologiese bene:

- daar word heuristies-interpretatief te werk gegaan in die verstaan van die situasie waarin skole en skoolhoofde neig om hulle deesdae te bevind, asook van die vraagstuk van performatiwiteit as sodanig;

- die kritiese benadering daarna berus op wat Alexander (2006: passim) ' $\mathrm{n}$ transendentaal-pragmatiese benadering noem. Met hierdie kritiese inset word gepoog om 'n bydrae maak tot die verbetering van die rol en werk van die skoolhoof (die "pragmatiese"). Dit word vanuit die transendentale hoek van 'n Christelikreformatoriese siening van die werk van 'n skoolhoof gedoen.

\section{Teoretiese vertrekpunte}

\subsection{Die veranderde rol en struktuur van die skool}

Stone (1981:8) het al enkele dekades gelede opgemerk dat skole oorspronklik ingestel is as opvoedende onderwysinstellings. In voorgeletterde gemeenskappe is hulle sporadies gebruik om die opkomende geslag in belangrike vaardighede op te lei soos om te jag of om teen grotwande te skilder. Inisiasieskole het soortgelyke oogmerke gehad, en het eintlik net gefunksioneer in tydperke van die oorgang tussen kindskap en volwassenheid, veral met die oog op die oordrag van gemeenskapsnorme (Mphahlele, 1992:7-9).

Skole het eers in die meer ontwikkelde beskawings van Sumerië, Athene en Rome hulle "moderne" beslag gekry. In die proses van die objektivering van kultuur het daar behoefte ontstaan aan 'n meer gespesialiseerde onderwysende/opvoedende instansie wat van ander samelewingsverbande soos die ouerhuis en die staat onderskei kon word. Met die intrede van spesialisering en diversifiëring in die samelewing het dit nodig geword dat daar 'n instansie moes kom wat sekere opvoedende onderwystake uit die hande van die ouers en die breë samelewing kon neem (Stone, 1981:8-9; Mphahlele, 1992:11 e.v.).

Uit die staanspoor, merk Stone (1981:15 e.v.) op, was daar meningsverskille oor die presiese doel en taak van die skool. Hierdie 
debat gaan vandag nog voort, soos 'n mens kan aflei uit die onlangse werk van Lagerwej en Lagerweij-Voogt (2005:95-260). Stone (1981:25) was self van oordeel dat die skool ontstaan het op grond van 'n kultureel-historiese organiseringshandeling (vgl. ook Taljaard, 1976:244). Die doel daarvan was die organisering van opvoedkundig-gefundeerde onderwys. In die onderwysproses moes die potensiaal van die leerders ontsluit word, veral hulle kognitiewe of analitiese vermoëns. ${ }^{2}$ Hoewel die nadruk op hierdie analities-onderwysende aspek was, moes die skole ook tot die opgevoedheid en volwassenheid van die kinders bydra (in die paideia-sin van die woord; vgl. Krüger \& Helsper, 2006:67). In wese was skole oorspronklik as didaskaleia gestruktureer, dit wil sê instansies gerig op die pedagogiese/opvoedkundige toerusting van die leerders deur middel van onderrig, van die onderrig-leergebeure (vgl. ook Goodlad, 1984:32).

Van der Westhuizen et al. $(2006: 67,71)$ sluit by die organisasiegedagte aan. Skole is na hulle oordeel nie net sosiale samelewingsverbande nie, maar ook organisasies. 'n Skool is 'n organisasie met die permanensie van 'n samelewingsverband. Die permanensiegedagte kom ook na vore uit die ontledings van skoolteorieë uit die penne van Lucas (1984:24) en Goodlad (1984). Nie een van die skoolteorieë of -benaderings wat hulle bespreek bring die permanensie van die skool in die gedrang nie. Om die waarheid te sê, die feit dat skole vandag nog ongehinderd voortbestaan, is 'n bewys daarvan dat die romantiserende pogings van die sogenaamde ontskolers van die laat sewentigerjare soos Holt, Reimer, Goodman en Illich misluk het (Lucas, 1984:15). In die plek daarvan het 'n ander verskynsel egter die wese van die skool begin bedreig, te wete performatiwiteit.

\subsection{Performatiwiteit, die skool en die rol van die skoolhoof}

Lyotard (1984:xxiv), die skepper van die term performatiwiteit en 'n navolger van Friedrich Nietzsche wat al aan die einde van die negentiende eeu die wirtschaftliche Gesamtverwaltung der Erde

2 Ravitch (2000) wys daarop dat die kerndoel van die skool, naamlik die intellektuele ontwikkeling of ontplooiing van die leerders, dikwels uit die oog verloor is gedurende die hervormings wat oor die eeue in die VSA se skoolstelsel plaasgevind het. In hierdie proses het daar soms ' $n$ verlaging in akademiese verwagtings ingetree. Volgens haar is die kerntaak van skole om kennis te onderrig. Hoewel Ravitch ander woorde as Stone gebruik (intellektuele ontwikkeling; onderrig van kennis) stem sy in beginsel saam dat dit in wese in die skool gaan oor die ontsluiting van die kognisie faset van die leerders. 
voorsien het, definieer performatiwiteit as die obsessie met efficiency and effectiveness (in 'n neoliberale, markgerigte geglobaliseerde wêreld, sou Verbrugge, 2004:49, byvoeg). Alle vorms van besigheid en handeling word gemeet en in rangordes geplaas, met min nadenke oor die rasionaal daaragter. Daar word soveel aandag aan meganismes gegee om doeltreffendheid te verhoog dat daar nie meer oor die redes daarvoor nagedink word nie. Dit is 'n simptoom van die "hoë moderniteit" waarin die mensdom hom tans bevind, meen Blake et al. (1998:1). Dit is moontlik ook simptomaties van 'n gebrek aan vertroue in die "werkers" in die skole, soos onderwysers en skoolhoofde (vgl. Fukuyama, 1996:9).

\section{Volgens Ball (2003:216) is performatiwiteit}

... a technology, a culture and a mode of regulation that employs judgements, comparisons and displays as means of incentive, control, attrition and change - based on rewards and sanctions (both material and symbolic). The performances (of individual subjects or organizations) serve as measures of productivity or output, or displays of 'quality', or 'moments' of promotion or inspection. As such they stand for, encapsulate or represent the worth, quality or value of an individual or organization within a field of judgement.

Ball se volgende stelling is van belang vir die diskussie wat hierna volg: "The issue of who controls the field of judgement is crucial" (kursivering - JLvdW et al.). 'n Mens vra jouself af wie die kriteria vir performatiwiteit in die hedendaagse skool bepaal. Is dit die betrokkenes by die skool self, of ander instansies soos die staat/owerheid deur sy onderwysdepartemente? ${ }^{3}$

Dit wil voorkom asof die eise van performatiwiteit ook skole in die afgelope tyd genoop het om as 't ware sakeondernemings te word. Performatiwiteit neig om die verskille tussen skole uit te skakel, sodat hulle onderling vergelyk kan word, en sodat almal volgens dieselfde standaarde toerekenbaar kan wees. Wat nie "operasio-

Soortgelyke gedagtes vind 'n mens ook by ondersoekers soos Webb (2006), Troman et al. (2007), Harris (2008), Nicholl en McLellan (2008), Clegg (2008) en andere. Nie alle ontleders van performatiwiteit beskou dit as noodwendig negatief nie, veral indien hulle nie besorg is oor die pedagogiese onderbou van die leer- en ander handelinge in die skole nie. In hierdie artikel staan die pedagogiese egter voorop. Die performatiwiteitseise van die bedryfswêreld word dus as onvanpas in en vir die skool beskou. Ball (2003), Sparkes (2007) en ander outeurs waarna meermale in hierdie bespreking verwys word, deel laasgenoemde siening. 
naliseerbaar" is nie, moet verdwyn. Assessering van uitsette ("wins") vind plaas in die vorm van byvoorbeeld matrikulasieslaagsyfers. In hierdie proses, sê Blake et al. (1998:2), word die opvoedende onderwys en sosiale en morele etos van die skool verwaarloos.

Hedendaagse skole vertoon inderdaad eienskappe van sakeondernemings (vgl. Vroom, 2002:58). 'n Sakeonderneming spesialiseer. Dit verdeel take in die organisasie tussen die verskillende spesialiste en sorg vir koördinasie tussen hulle. Dit werk met gestandardiseerde prosedures, prosesse, standaarde en roetines met die oog op effektiewe besluitneming. Dit omskryf die deelnemers se rolle en hoe hulle taakverrigting beoordeel moet word. Dit benut handleidings om inligting en prosedures te formaliseer. Dit toon besluitnemingsvlakke en bevoegdhede aan. Dit konfigureer ook die verskillende take, pligte, funksies en posisies in 'n hiërargiese organisasiestruktuur (Mintzberg, 1979:18).

As "sakeonderneming" funksioneer 'n skool in 'n bepaalde konteks en in 'n bepaalde gemeenskap. Die "kliëntebasis" daarvan kom uit hierdie gemeenskap. Dit werk ook in 'n statutêre raamwerk en word dikwels deur interne politiek en magstryde geteister (Morgan, 1997: 172; Senior, 2002:174; Jooste, 2004:219; Hofstede, 2002:68; Coleman, 2005:63; Wilson, 2004:184; Robbins, 2001:510; Werner, 2003a:24). Skole maak sedert die negentigerjare ook toenemend gebruik van dienste van buite (outsourcing), 'n vorm van uitkontraktering in die markomgewing. Dit het moontlik geword omdat skole hulle eie inkomstes en begrotings hanteer en gebruik mag maak van mededingende tenderaksies vir die voorsiening van goedere en dienste (vgl. Davies, 2004:223). In sekere opsigte het skole die organiseerders en benutters van dienste geword, in plaas van die verskaffers van dienste wat die onderwysfunksie ondersteun (Breed, 2008:123).

\subsection{Die skoolhoof as "hoofuitvoerende beampte" (HUB) van sy "besigheid"}

Tot en met die sewentigerjare, meen Fidler en Atton (2004:18), is die skoolhoof as die professionele leier van die skool as opvoedende onderwysinstansie beskou. Sedertdien het groterwordende skole en die eise van performatiwiteit tot gevolg gehad dat skoolhoofde hulself sien, en deur ander gesien word, as die HUB's van hulle skole. Hulle het, om die woorde van Ball (2003:219) te gebruik, die "helde van performatiewe opvoedkundige hervorming" geword. Terme soos institusionele devolusie, site-based management, entrepreneuriese beheer deur bemarking en mededingende voordeel het 
deel van hulle woordeskat geword, van hulle management speak gebore uit hulle business world ideology (Sparkes, 2007:528; vgl. ook Troman et al., 2007: passim). Om met die instrumente van performatiwiteit te werk, het hulle daaglikse brood en botter geword: moniteringsisteme, informasieproduksie, vorming van databasisse, assesseringsvergaderings, jaarlikse oorsig en verslagdoening, die publikasie van resultate, aanstellings en bevorderings, inspeksies en portuurevaluerings - om maar net 'n paar te noem (Ball, 2003:230). Daar word na die personeel verwys as "menslike kapitaal of hulpbronne" (Welch, 1998:3). Om hulle "besighede" in stand te hou, werp skoolhoofde alles in die stryd om die leerdertal konstant te hou of te laat groei, om die fondse te laat groei, om goeie prestasies te lewer, en om die beste personeel vir dié doel te werf.

Hierdie nuwe neiging is deur twee omstandighede in die hand gewerk. Aan die een kant is dit bevorder deur 'n verlies aan seggenskap en besluitneming oor kurrikulumsake. Alles is ooreenkomstig performatiewe norme van "bo-af" gereël, tesame met massas administrasie asook "a policing of scholarship" (Sparkes, 2007: 524). Aan die ander kant is dit bevorder deur 'n byna volledige beheer oor die eie finansies vir die bedryf van die skool. Die verdere $90 \%$ wat vir die bekostiging van onderwysersalarisse benodig word, kom in die openbare skole van die kant van die staat - vandaar dat die staat/owerheid vir alle praktiese doeleindes as "eienaar" op die skool beslag lê en dit aan performatiwiteitseise onderwerp. Omdat daar nie meer so iets soos skoolgrense bestaan nie, en ouers dus 'n vrye keuse van skole het, kom bemarking ook sterker in die prentjie.

Alhoewel baie van die optredes en take van die skoolhoof vandag nog steeds ooreenstem met die tradisionele taak van die skoolhoof, het daar tog 'n subtiele verandering ingetree. Daar het 'n verskuiwing plaasgevind vanaf die didaskaleion-aard van die skool na die performatiewe aard daarvan. Dit merk 'n mens uit die organisasiestruktuur van die skool. Skole neig tans om, soos besighede of sakeondernemings, hiërargies georganiseer te word, met die leerders op die heel onderste vlak en die verskillende pos- en bevoegdheidsvlakke hiërargies daarbo georganiseer: die graadhoof, die vakhoof, die departementshoof, die visehoof, die adjunkhoof, die skoolhoof as die HUB. Alles is daarop gerig om die grootste wins te maak, hetsy in die vorm van slaagsyfers, onderskeidings, of die wen van 'n prestigetrofee (Werner, 2003b:186). Sonder om in besonderhede in te gaan, kan gekonstateer word dat skole deesdae in die praktyk aandag moet gee aan dieselfde praktyke as sakeondernemings (vgl. Buchanan \& Huczynski, 1997:397; Mintzberg, 1973: 
55; Kelly, 2000:92; Werner, 2003a:249; Chin \& Benne, 1994: 122; Senior, 2002:277; Sharpe, 2004:44, 49; Hodge \& Anthony, 1991:529; Morgan, 1997:167; Keuning \& Eppink, 1996:369, 513; Lawler et al., 1998:56; French, 1994:301; Robbins, 2001:499; Bagraim, 2003:52; Potgieter, 2003:207; Den Hertog \& Tolner, 2002:402; Kossler \& Kanaga, 2004:236).

\section{Empiriese ondersoek}

Om die vermoede te toets dat skoolhoofde neig om hulself eerder as leiers van sakeondernemings te sien (HUB's) en nie eintlik meer as die leiers van didaskaleion-instansies nie, het Breed (2008) 'n empiriese ondersoek ingestel onder 'n verteenwoordigende steekproef van skoolhoofde in die Gauteng-provinsie. Hy het gesorg vir die stiptelike nakoming van Jaeger (1988:326) se riglyne vir substantiewe veralgemening. Dit kan dus veronderstel word dat hierdie bevindings bes moontlik ook van toepassing is op die situasie van skoolhoofde in die ander provinsies van Suid-Afrika, en moontlik ook in ander wêrelddele.

Die empiriese ondersoek hoef nie vir die doel van hierdie argumentasielyn in besonderhede beskryf te word nie (vgl. Breed, 2008 vir 'n volledige uiteensetting). Die fokus is op die feit dat die vraelys ' $n$ item bevat het (item 3.24, een van 49 items in afdeling $B$ van die vraelys) wat soos volg lui: "As skoolhoof voel ek soms/net elke nou en dan/dikwels/heel dikwels dat my leierskapsrol goed vergelyk kan word met die bestuur van 'n besigheid/sakeonderneming." Die ander 48 items kon ewe goed deur 'n skoolhoof as pedagogiese leier óf deur 'n HUB van 'n sakeonderneming ingevul word, en die response sou in 'n hoë mate ooreenstem. Die response op item 3.24 was dus van deurslaggewende belang: indien die meeste van die skoolhoofde sou respondeer met "soms" of "net elke nou en dan", sou 'n mens kon aflei dat hulle hulle taak nog hoofsaaklik sien as dié van leiers van 'n didaskaleion-instansie ('n opvoedende instansie). Indien die meeste egter sou respondeer met 'n "dikwels" of "heel dikwels", kon 'n mens aflei dat hulle inderdaad aan die swig is voor die eise van performatiwiteit, en dat hulle hulle taak eerder sien as dié van HUB's van hulle skole.

Laasgenoemde was wel inderdaad die geval: $35,6 \%$ het met "dikwels" gerespondeer, en 51,3\% met "heel dikwels" - in totaal 86,9\% van al die respondente in 'n veelkansige verteenwoordigende steekproef van Gautengse skoolhoofde. Dit dui daarop dat die skoolhoofde neig om hulself as die HUB's van hulle skole te sien, en dat hulle die eise van performatiwiteit aan hulle professionele lywe voel. 


\section{Performatiwiteit: 'n kritiese opvoedingsfilosofiese beoordeling}

Daar bestaan drie kernbesware of -argumente teen performatiwiteit in die onderwys in skole:

- die reduksionistiese aard daarvan;

- die onpedagogiese aard daarvan; en

- die onvanpaste samelewingsteoretiese aard daarvan.

Hierdie drie argumente teen performatiwiteit in die algemeen, en veral in die konteks van die skool, word agtereenvolgens aangebied.

\subsection{Die reduksionistiese aard van performatiwiteit}

Volgens Christelik-reformatoriese opvattings is die mens volledig mens, beeld van God, 'n wese met 'n hele aantal fasette, soos die religieuse, die etiese, die sosiale en relasionele, die psigiese, die ekonomiese of bedryfsfasette - om maar enkeles te noem - en met baie onontginde godgegewe potensiaal. Vir die volledige ontwikkeling van die mens is dit noodsaaklik dat al hierdie fasette van menswees ten volle ontplooi word. In 'n opvoedingskonteks gaan dit dus in die eerste plek oor die mens (Sparkes, 2007:521). Die mens is meer as sy/haar prestasie soos dit op 'n stuk papier geformuleer staan (vgl. Sparkes, 2007:528). In 'n performatiwiteitsomgewing (onder meer gekenmerk deur 'n "ouditkultuur"; vgl. Sparkes, 2007: 521, passim) word die mens egter net ter wille van sy/haar produktiwiteit waardeer. Outentieke menslike vryheid en bande met ander mense word geringgeskat, en die waarde van die mens as 'n individu word selfs "uitgewis" (Ball, 2003:224).

Performatiwiteit is, ontologies-antropologies gesproke, reduksionisties van aard. Dit lê die nadruk op slegs een faset van die mens en menslike handeling, naamlik meetbare prestasie. Om prestasie te kan meet, so lui die teorie van performatiwiteit, moet die prosesse wat daartoe lei gestandaardiseer en gehomogeniseer wees. Almal wat by die betrokke handeling betrokke is (soos die bestuur van 'n skool), moet aan die hand van dieselfde norme, riglyne en standaarde aanspreeklik gehou word. Dit wat buite hierdie raamwerk val, moet uitgeskakel word. Wanneer die reduksionisme van performatiwiteit ' $n$ organisasie insypel, bevind Ball (2003:218), begin die betrokkenes in die organisasie 'n nuwe taal praat. Die onderwysorganisasie raak "bevolk" met menslike "hulpbronne" wat "bestuur" moet word. Leer word "koste-doeltreffende beleidsuitkomste"; prestasie 
word "produktiwiteitsteikens"; leerders leer "selfstandig" sodat opvoeders "fasiliteerders, voorsieners, produksiewerkers en onderwysondernemers" word. Skoolhoofde word aan gereelde "appraisal and review and performance comparisons" onderwerp. Pedagogiese terme word as lastig en selfs obstruktief beskou.

Performatiwiteit het 'n vaal eenselwigheid tot gevolg. Alle skoolhoofde word nagenoeg aan dieselfde standaarde van handeling en optrede onderwerp. Hulle verdere bevordering hang af van die mate van nakoming van die gestelde standaarde. Hulle prestasies moet gemeet kan word, en dit moet onderling vergelykbaar wees. (So kan 'n mens byvoorbeeld in die koerant lees watter skole in 'n betrokke jaar se graad 12-eksamens die beste gevaar het. In die Verenigde Koninkryk en die VSA word hulle selfs in 'n rangorde van uitnemendheid geplaas.)

Performatiwiteit reduseer die werk van die skoolhoof tot gestandaardiseerde prosesse en handelinge wat aan die hand van tasbare uitsette gemeet kan word. Performatiwiteit haal die essensies van menswees uit die bedrywighede van die skool, en daarmee word die eise wat byvoorbeeld in 1 Korintiërs 4:1-2 gestel word, verontagsaam. Dit ontken die gedagte van die mens as holon, dit wil sê 'n totale geheelwese wat uit verskillende aspekte en eienskappe bestaan, maar wat tegelyk deel is van 'n groter geheel (vgl. Wielemans, 1993:179), soos die samelewing waartoe hy/sy behoort. Performatiwiteit, stel Wielemans (1993:178-179), relativeer die eiestandigheid en selfontplooiing van die mens tot slegs een dimensie van die omvattende dinamiek waaraan die mens deel het. Die performatiewe beklemtoning van selfgelding en wedywering moet derhalwe van die hand gewys word as ' $n$ vorm van antropologiese en kulturele eensydigheid.

\subsection{Performatiwiteit is onvanpas in 'n opvoedingsomgewing}

Indien 'n mens opvoeding definieer as die toerusting, leiding en begeleiding van 'n relatief onvolwasse persoon ('n kind/leerder in 'n skool) deur 'n relatief meer volwasse persoon ('n ouer, of onderwyser/opvoeder in 'n skool), is performatiwiteit onvanpas in 'n opvoedingskonteks. Die gevaar bestaan dat performatiwiteit nie voldoende ruimte laat vir die omgee vir ander mense nie, soos die leerders. Die belangrikste "omgee" is hoedat gepresteer kan word, of "excellence" (uitnemendheid) bereik kan word (Ball, 2003:224).

Die leiding van 'n opvoedeling tot roepingsvervulling in diens van God en die naaste (rentmeester van God; vgl. Gal. 5:13) kan nie in 
die reduksionistiese atmosfeer van performatiwiteit plaasvind nie. Performatiwiteit berus op die aanname dat die waarde van die opvoedeling, die opvoeding en onderwys gereduseer kan word tot ekonomiese terme en waardes (Verbrugge, 2004:53). Mense wat by skole betrokke is, het hoofsaaklik waarde weens hulle vlakke van opgevoedheid en die vaardighede waaroor hulle beskik (Welch, 1998:3). Een van die gevolge van hierdie "opvoedingsfilosofie" is dat hoewel daar oënskynlik omgegee word vir andere soos medeopvoeders en die leerders, hierdie "omgee" eintlik op manipulasie en oneerlike "fabrikasies" en "speletjies" neerkom om die gestelde performatiewe doelwitte te bereik (Ball, 2003:224-25). In hierdie proses is dit nie altyd duidelik wie die manipuleerders is en wie gemanipuleer word nie.

In 'n ware opvoedingskonteks is baie dinge nie meetbaar nie. Die opvoedeling is toegerus met 'n breed-geskakeerde totaliteit vermoëns en potensiaal, en dit moet alles tot volle ontplooiing gebring word deur die opvoedende (dit is: toerustende en begeleidende) handeling van die opvoeder. Volledige opvoeding kan nie geskied wanneer die onderwysleier se fokus beperk bly tot die eise van performatiwiteit nie. Ball (2003:225) merk tereg hieroor op: "The heart of the educational project is gouged out and left empty." Sparkes (2007:521) stem saam: Opvoeders wat toegee aan die eise van performatiwiteit voel "empty, despondent, disillusioned. They (feel) spiritually and ethically bankrupt". In 'n opvoedende onderwysomgewing is dit nie eintlik moontlik om presiese performatiewe uitsette voor te skryf nie. Hoe skryf 'n mens byvoorbeeld die stadium van die bereiking van morele volwassenheid voor (vgl. Ex, 2007:34 e.v.)?

Performatiwiteit kan gedy in 'n skool waar slegs analitiese of kognitiewe ontsluiting in die visier is. Goodlad (1984:32) het reeds etlike dekades gelede opgemerk:

Schools must do the educating not consciously done elsewhere in society. This includes providing systematic encounters with all the domains of knowledge, encounters designed to inform, enlighten and stimulate thought.

In die skool lê die nadruk op die bybring van kennis, hetsy deur dit "oor te dra aan die leerders" of om die leerders te help om dit vir hulself te konstrueer (vgl. Elmore et al., 1996: passim). In 'n opvoedingskonteks behoort dit egter oor méér as net die bybring van kennis of inligting te gaan, oor meer as net die ontsluiting van die kognitiewe of analitiese aspek van die leerders. Dit is waarom 
Goodlad (1984:32) opmerk: "... schools are not likely to go beyond teaching facts and fundamental skills unless we ask them to" (kursivering - JLvdW et al.). Hy impliseer met hierdie opmerking dat die onderwys in die skool ook opvoedend behoort te wees; dit is: volledig toerustend en voorbereidend vir die wêreld van die volwassene. Van Crombrugge (2006:97) vat hierdie gedagte soos volg saam: die opvoeder "laten groeien of snoeien om te bloeien".

Performatiwiteit veroorsaak voorts dat opvoeders/onderwysers en leerders se verhouding met die leerinhoude en akademiese werk inherent verander. In plaas daarvan dat kennis en inligting die medium of voertuig is aan die hand waarvan opvoedende onderwys gegee word, lei performatiwiteit tot die kommodifisering van kennis en inligting (Lyotard, 1984:4). Kennis word dus geëksternaliseer tot die opvoedingshandeling. Dit word ' $n$ verhandelbare produk, en nie meer die instrument aan die hand waarvan opvoedende onderwys kan geskied nie. Lyotard (1984:51) het waargeneem dat die aandag verskuif het vanaf: Is dit waar? Kan dit my beter toerus vir my roeping? na: Is dit verkoopbaar? Is dit nuttig?

\subsection{Performatiwiteit is onvanpas in 'n propedeutiese en "didaskaleion"-omgewing}

Ook vanuit 'n samelewingsteoretiese gesigspunt kan 'n mens kritiek teen performatiwiteit uitspreek. Die skool as samelewingsverband verskil wesenlik van 'n bedryfsorganisasie soos 'n besigheid. Dit merk 'n mens uit hulle onderskeie oogmerke. Die skool se doel, soos hierbo aangetoon, is om in die gespesialiseerde taak van onderwys te voorsien, dit wil sê die bybring van kennis, inligting en vaardighede aan die opkomende geslag. Hierdie kennis, inligting en vaardighede is nodig om die opvoedelinge voor te berei vir die uitdagings van 'n volwasse lewe in diens van God en die medemens, hetsy in die vorm van verdere studie of in die werksplek. 'n Skool maak in beginsel geen finansiële wins nie.

Hoewel daar, soos Breed $(2008: 86,126)$ bevind het, ooreenkomste bestaan tussen die bedryf van en die leierskap in respektiewelik 'n skool en 'n bedryfsorganisasie, is daar 'n fundamentele verskil tussen hulle. Die skool is 'n onderwysende instansie, gerig op die kognitief-analitiese ontsluiting van die leerders se potensiaal, en die "wins" wat daar gemaak word is die mate waarin hierdie ontsluiting by die leerders plaasvind. 'n Bedryfsorganisasie maak finansiële wins. Sowel die skool as die bedryf of besigheid kom tot stand deur die een of ander kultuur-historiese organiseringshandeling in die gemeenskap, gewoonlik 'n daad van oprigting of instituering. Daar 
eindig die ooreenkomste egter. Die oogmerke met die verskillende samelewingsverbande in 'n bepaalde samelewing verskil tot so 'n mate dat daar al in die verlede sprake was van die "beginsel" van soewereiniteit in eie kring ("de grenzen van sferen"; Verbrugge, 2004:74).

Onderwys is nie tot die skool gereserveer nie. Daar is ook kerkonderwys, staatsonderwys en bedryfsonderwys (byvoorbeeld die opleiding van vakleerlinge in ' $n$ fabriek). Opvoeding is ook nie tot die skool gereserveer nie. Ouers (die ouerhuis), onderwysers (die skool), beamptes in gevangenisdienste (die staat), dosente (die universiteit en kollege), en ook sakeleiers (die bedryf) voed almal op. Alle samelewingsverbande het dus 'n opvoedingstaak onder die doelfunksie van die betrokke samelewingsverband.

Indien onderwys sowel as opvoeding dan nie die spesialistaak van die skool is nie, wat is sy taak dan? Die feit dat skole deur die eeue bly voortbestaan het, is 'n bewys daarvan dat die skool nog altyd in samelewingsverbandelike sin 'n nisfunksie vervul het.

Wat is hierdie besondere nis? 'n Besinning oor die rol, taak en plek van die skool in 'n moderne samelewing toon dat die nis die volgende eienskappe vertoon daar is behoefte aan 'n samelewingsverband:

- wat onderwys (onderrig- en leeraktiwiteite) aan jongmense tussen die ouderdomme van ongeveer 6 en 18 jaar kan bied;

- wat opvoedende (algemeen toerustende) handelinge tot voordeel van jongmense in hierdie ouderdomsgroep kan verrig;

- wat inligting, kennis, vaardighede en gesindhede by hulle kan bybring; en

- waar sodanige inligting nie van die gespesialiseerde aard is wat benodig word in ander samelewingsverbande soos die ouerhuis, die kerk, die staat, die bedryf of spesialisonderwysinstansies soos universiteite en kolleges nie.

Die werk van die skool as opvoedende onderwysinstansie is met ander woorde van 'n voorbereidende aard.

Dit wil dus voorkom asof die besondere nis van die skool opgesluit is in twee fasette: die feit dat dit kan fokus op die didaskaleion ten aansien van jongmense, en dat dit propedeuties van aard is - dus voorbereidende opvoedende onderrig-leer bied wat vir die ander 
samelewingsverbande as onderbou kan dien. Nie een van die ander samelewingsverbande kan hierdie propedeutiese funksie vervul nie.

Die term propedeuties is afgelei uit die Griekse propaideuein - om vooraf op te lei of voor te berei (die Griekse woorde self is afgelei uit pro- vooraf, en paideuein, om groot te maak, op te voed) (Sinclair, 1999:1184). lewers tussen al die ander gevestigde samelewingsverbande (kerk, skool, staat en bedryf) is daar 'n samelewingsverband wat die propedeutiese funksie ten opsigte van jongmense moet verrig waarsonder die ander samelewingsverbande nie hulle eie onderskeie oogmerke kan bereik nie.

As voorbereidende opvoedende onderwysinstansie (en ook as didaskaleion - instansie gerig op die pedagogiese voorbereiding van jongmense (leerders) deur middel van onderrig en leer) het die skool 'n eie pedagogiese waardestelsel. Hierdie waardestelsel word deur die eise van performatiwiteit bedreig. In teenstelling met die performatiwiteitswaardes wat die staat/owerheid neig om op skole af te dwing (Sparkes, 2007:534; vgl. ook Rosenzweig, 1994:16 ten opsigte van universiteite), soos institusionele selfbelang, pragmatika en performatiewe waarde, behoort die skool te fokus op die pedagogiese waardes wat uit propaideuein en didaskaleion vloei. In plaas van 'n etiek van mededinging en performance behoort die skool terug te keer na sy eie etiek van professionele oordeel en samewerking (Ball, 2003:218).

In 'n performatiwiteits-organisasiekultuur is daar nie juis ruimte vir pedagogiese vryheid nie, en dit kan onderwysers vervreem. Een onderwyseres in die Verenigde Koninkryk het onlangs verklaar:

I never get the chance to think of my philosophy any more, my beliefs. I know what I believe but I never really put them into words anymore. Isn't your philosophy more important than how many people get their sums right? (Ball, 2003:222).

"Beliefs are no longer important - it's output that counts. Beliefs are part of an older, increasingly displaced discourse", som Ball (2003: 223) die situasie op.

Die skoolhoof behoort 'n bestuurs- en leierskapstyl te hê wat ooreenstem met die skool se nis in die samelewing. Die skoolhoof behoort hom-/haarself te sien as betrokke by die propedeutiese voorbereiding van die leerders in die skool. Hy/sy is iemand wat 'n niswerk in die samelewing verrig waarsonder ander samelewingsverbande nie kan klaarkom nie. Die skool speel dus nie volgens die reëls van die bedryf se performatiwiteitspel nie - nie eens onder die 
aandrang van die staat/owerheid as samelewingsverband nie. Dit speel die spel volgens die reëls van sy eie propedeutiese nis of funksie. Dit is 'n selfstandige samelewingsverband met sy eie funksies en oogmerke.

\section{Gevolgtrekking en aanbeveling}

'n Oorsig van die literatuur oor die bestuur en bedryf van skole het aan die lig gebring dat skoolhoofde toenemend druk ervaar om hulle skole te bestuur en leierskap in skole te gee wat aan performatiwiteitseise sal voldoen. Verreweg die grootste persentasie van die skoolhoofde in die Gauteng-provinsie van Suid-Afrika het skynbaar reeds voor die druk hiervan geswig. Vanuit 'n Christelik-reformatoriese siening van die struktuur van samelewingsverbande, is die oortuiging egter dat hierdie neiging in beginsel foutief is, aangesien dit inbreuk maak op die selfstandigheid van die skool as samelewingsverband.

Die skool is 'n sagte teiken vir die kritici daarvan. Die rede vir hierdie "sagtheid" lê daarin dat die betrokkenes by skoolonderwys, insluitend skoolhoofde, selde 'n duidelike opvatting het van die propedeutiese nis van die skool in die samelewing. Weens hierdie gebrek aan insig bevind die skool hom gevolglik dikwels onder die hiel van ander samelewingsverbande.

Deur performatiwiteit op die skool af te dwing, is hier met 'n subtieler vorm van "kolonialisering" (afgelei uit die Lat. colere, om te bewerk en te bewoon) te make. Die waardes van die bedryfsorganisasie "woon" en "werk" - ten onregte - in die skool, en selfs in die onderwysers se persoonlike lewens (Ball, 2003:221). Die staat/owerheid tree in hierdie proses op soos "a myriad of well-wishing 'little sisters' ... who know who we are, who have invaded all realms of life" (Castells, 1998:301).

In die geval van openbare of staatskole word die skool burokraties aan die implisiete waardestelsel van die staatsburokrasie onderwerp (Blake et al., 1998:132-133). Selfs die woord waarde is deur die staatsburokrasie gekaap. In plaas van die betekenis wat in godsdienstige en etiekkringe daaraan geheg word, word dit deesdae aan skole deurgegee in die gewaad van performance indicators. Daarmee, meen Ball (2003:216), word die distinctiveness (onderskeidendheid) van die skool as samelewingsverband verminder.

Hierdie neiging verjaag onderwysers wat verstaan waaroor dit in die skool behoort te gaan, uit die skole. Ball (2003:216) haal die vol- 
gende rede van 'n Britse onderwyseres aan waarom sy opgehou het om skool te hou: "I was a primary school teacher for 22 years but left in 1996 because I was not prepared to sacrifice the children for the glory of politicians and their business plans for education." 'n Ander persoon het opgemerk: "It's as though children are mere nuts and bolts on some distant production line, and it angers me to see them treated so clinically in their most sensitive and formative years." Albei hierdie onderwyseresse het raakgesien dat die skool sy propedeuties-didaskaleion-aard opgeoffer het ten gunste van performatiwiteit. Soos Bernstein (1996:169) tereg opmerk: "contract replaced covenant".

Die gevare van performatiwiteit in die skole moet weerstaan word. Skoolhoofde staan in die eerste linie van verdediging. Hulle behoort meer bewus te wees van die besondere propedeutiese en didaskaleion-aard van hulle skole en behoort maniere te vind om hulle teen die performatiwiteitseise te verset. Dit is juis die eise van performatiwiteit wat onderwysers tans onder papierwerk en administrasie verswelg, en hulle teikens laat najaag wat vir baie onbereikbaar skyn te wees - en wat in beginsel buite die bestek van die skool as propedeutiese instansie in die samelewing lê.

\section{Geraadpleegde bronne}

ALEXANDER, H. 2006. A view from somewhere: explaining the paradigms of educational research. Journal of philosophy of education, 40(2):205-221.

BAGRAIM, J. 2003. Motivating the South African workforce. (In Schultz, H., ed. Organizational behaviour: a contemporary South African perspective. Pretoria: Van Schaik. p. 51-71.)

BALL, S.J. 2003. The teacher's soul and the terrors of performativity. Journal of education policy, 18:215-228.

BERNSTEIN, B. 1996. Pedagogy: symbolic control and identity. London: Taylor \& Francis.

BLAKE, N., SMEYERS, P., SMITH, R. \& STANDISH, P. 1998. Thinking again: education after postmodernism. Westport: Bergin \& Harvey.

BREED, J.A. 2008. Die leierskapsrol en -bevoegdhede van die skoolhoof en die bedryfsleier: 'n vergelykende studie. Potchefstroom: Noordwes-Universiteit. (Ph.D.-proefskrif.)

BUCHANAN, D. \& HUCZYNSKI, A. 1997. Organizational behaviour: an introductory text. New York: Prentice-Hall.

CASTELLS, M. 1998. The power of identity. Malden: Blackwell.

CHIN, R. \& BENNE, K.D. 1994. General strategies for effecting changes in human systems. (In French, W.L., Bell, C.H. \& Zawacki, R.A., eds. Organization development and transformation: managing effective change. Boston: Irwin. p. 111-132.)

CLEGG, S. 2008. Academic identities under threat? British educational research journal, 34(3):329-345. 
COLEMAN, M. 2005. Organisations: power, structure and culture. (In Coleman, M. \& Early, P., eds. Leadership and management in education: cultures, change and context. Oxford: Oxford University Press. p. 47-65.)

DAVIES, B. 2004. Rethinking schools and school leadership for the twenty-first century. (In Tomlinson, H., ed. Educational management: major themes in education. New York: RoutledgeFalmer. p. 219-237.)

DEN HERTOG, F. \& TOLNER, T. 2002. Groups and teams. (In Sorge, A., ed. Organization. London: Thomson Learning. p. 402-415.)

ELMORE, R., PETERSON, P.L. \& MCCARTHEY, S.J. 1996. Restructuring in the classroom: teaching, learning and school organisation. San Francisco: Jossey-Bass.

EX, C. 2007. Opvoeden: wat kun je? Amsterdam: Wereldbibliotheek.

FIDLER, B. \& ATTON, T. 2004. The headship game: the challenges of contemporary school leadership. London: RoutledgeFalmer.

FRENCH, W.L. 1994. A history of organization development. (In French, W.L., Bell, C.H. \& Zawacki, R.A., eds. Organization development and transformation: managing effective change. Boston: Irwin. p. 25-40.)

FUKUYAMA, F. 1996. Trust: the social virtues and the creation of prosperity. New York: Free Press.

GOODLAD, J.I. 1984. A place called school. New York: McGraw-Hill.

HARRIS, B 2008. Befriending the two-headed monster: personal, social and emotional development in schools in challenging times. British journal of guidance and counselling, 36(4):367-383.

HODGE, B.J. \& ANTHONY, W.P. 1991. Organization theory: a strategic approach. Boston: Allyn \& Bacon.

HOFSTEDE, G. 2002. Organization culture. (In Sorge, A., ed. Organization. London: Thomson Learning. p. 68-91.)

JAEGER, R.M. 1988. Complementary methods for research in education. Washington: American Educational Research Association.

JOOSTE, K. 2004. Leadership: a new perspective. Journal of nursing management, 12:217-223.

KELLY, D. 2000. Using vision to improve organizational communication. Leadership \& organisation development journal, 21(2):92-101.

KEUNING, D. \& EPPINK, D.J. 1996. Management organisatie: theorie en toepassing. Amsterdam: Stenfert Kroese.

KOSSLER, M.E. \& KANAGA, K. 2004. Creating teams that work. (In Wilcox, M. \& Rush, S., eds. The CCL guide to leadership in action: how managers and organizations can improve the practice of leadership. San Francisco: Wiley. p. 235-257.)

KRÜGER, H-H. \& HELSPER, W. 2006. Einführung in Grundbegriffe und Grundfragen der Erziehungswissenschaft. Opladen: Barbara Budrich.

LAGERWEIJ, N. \& LAGERWEIJ-VOOGT, J. 2005. Anders kijken. Antwerpen: Garant.

LAWLER III, E.E., MOHRMAN, S.A. \& LEDFORD, G.E., Jr. 1998. Strategies for high performance organizations: employee involvement, TQM, and reengineering programs in fortune 1000 corporations. San Francisco: Jossey-Bass.

LUCAS, C.J. 1984. Foundations of education. Englewood Cliffs: Prentice-Hall.

LYOTARD, J.F. 1984. The postmodern condition: a report on knowledge. Manchester: Manchester University Press. 
MINTZBERG, H. 1973. The nature of managerial work. New York: Harper \& Row.

MINTZBERG, H. 1979. The structuring of organizations. Upper Saddle River: Prentice-Hall.

MORGAN, G. 1997. Images of organizations. London: Sage.

MPHAHLELE, M.C.J. 1992. Education through the ages. Pretoria: HAUM.

NICHOLL, B. \& MCCLELLAN, R. 2008. We're all in this game together whether we like it or not to get a number of A'c to C's: design and technology teachers' struggles to implement creativity and performativity policies. British educational research journal, 34(5):585-600.

POTGIETER, T. 2003. Stress management, well-being and job satisfaction. (In Schultz, H., ed. Organizational behaviour: a contemporary South African perspective. Pretoria: Van Schaik. p. 206-226.)

RAVITCH, D. 2000. Left back: a century of failed school reforms. New York: Simon \& Schuster.

ROBBINS, S.P. 2001. Organizational behaviour. 9th ed. Upper Saddle River: Prentice-Hall.

ROSENZWEIG, R.M. 1994. The permeable university: academic life in an age of special interests. Interchange, 25(1):11-17.

SENIOR, B. 2002. Organizational change. Essex: Pearson.

SHARPE, D. 2004. Getting a grip on conflict. (In Wilcox, M. \& Rush, S., eds. The CCL guide to leadership in action: how managers and organizations can improve the practice of leadership. San Francisco: Wiley. p. 44-55.)

SINCLAIR, J.M. 1999. Collins Concise Dictionary. Glasgow: Harper-Collins.

SPARKES, A.C. 2007. Embodiment, academics, and the audit culture: a story seeking consideration. Qualitative research, 7:521-550. http://qrj. sagepub.com/cgi/content/abstract/7/4/521 Date of access: 11 Dec. 2007.

STONE, H.J.S. 1981. Die aard en struktuur van die skool. Pretoria: Academica.

TALJAARD, J.A.L. 1976. Polished lenses. Potchefstroom: Pro Rege.

TROMAN, G., JEFFREY, B. \& RAGGL, A. 2007. Creativity and performativity policies in primary school cultures. Journal of educational policy, 22(5):549-572.

VAN CROMBRUGGE, H. 2006. Denken over opvoeden. Antwerpen: Garant.

VAN DER WESTHUIZEN, P.C., ERASMUS, M., JANSON, C.A., MENTZ, P.J. \& THERON, A.M.C. 2006. Schools as organisations. Pretoria: Van Schaik.

VERBRUGGE, A. 2004. Tijd van onbehagen. Amsterdam: SUN.

VROOM, C. 2002. Organization structure. (In Sorge, A., ed. Organization. London: Thomson Learning. p. 54-67.)

WEBB, P.T. 2006. The choreography of accountability. Journal of educational policy, 21(2):201-214.

WELCH, A.R. 1998. The cult of efficiency in education: comparative reflections on the reality and the rhetoric. Comparative education, 34(2):157.

WERNER, A. 2003a. Organizational change and innovation. (In Schultz, H., ed. Organizational behaviour: a contemporary South African perspective. Pretoria: Van Schaik. p. 248-263.)

WERNER, A. 2003b. Organizational culture, ethics and diversity in a global environment. (In Schultz, H., ed. Organizational behaviour: a contemporary South African perspective. Pretoria: Van Schaik. p. 21-35.)

WIELEMANS, W. 1993. Voorbij het individu. Leuven-Apeldoorn: Garant.

WILSON, F.M. 2004. Organizational behaviour and work: a critical introduction. New York: Oxford University Press. 


\section{Kernbegrippe:}

onderwysbestuur

opvoedingsfilosofie

performatiwiteit

skool

\section{Key concepts:}

educational management

performativity

philosophy of education

school 
